\title{
PROFIL HABITS OF MIND MAHASISWA PROGRAM STUDI PENDIDIKAN MATEMATIKA FKIP UNIVERSITAS BATANGHARI JAMBI
}

\author{
Eni Defitriani ${ }^{1}$ \\ Program Studi Pendidikan Matematika FKIP UNBARI, Jl. Slamet Riyadi No. 1 Jambi ${ }^{1}$ \\ e-mail: eni.defitriani@unbari.ac.id
}

\begin{abstract}
ABSTRAK
Habits of Mind memiliki peranan penting dalam proses pembelajaran dan perkembangan individu dalam memecahkan masalah. Kebiasaan ini yang menjadi akar kekuatan siswa dalam melatih kemampuan mereka dalam menemukan solusi dari permasalahan yang dihadapi. Penelitian ini bertujuan untuk mendeskripsikan profil habits of mind mahasiswa prodi pendidikan matematika. Jenis penelitian yang digunakan adalah deskriptif dengan pendekatan kuantitatif. Populasi penelitian adalah mahasiswa prodi pendidikan matematika FKIP UNBARI. Sampel terdiri dari 33 orang yang dipilih secara stratified random. Instrumen yang digunakan adalah angket HoM yang disebar secara online. Analisis data dilakukan secara kuantitatif. Hasil penelitian menunjukkan bahwa habits of mind mahasiswa berada pada kategori baik dengan persentase 75,39\%
\end{abstract}

Kata kunci :

Habits of Mind, Profil

\begin{abstract}
Habits of Mind has an important role in the learning process and individual development in solving problems. This habit is the basic of students' strength in practicing their ability to find solutions to the problems they face. This study aims to describe the habits of mind profile of mathematics education study program students. The type of research used is descriptive quantitative approach. The population was students of mathematics education study program FKIP UNBARI. The sample consisted of 33 people selected by stratified random. The instrument used was the HoM questionnaire distributed online. Data analysis was carried out quantitatively. The results was the habits of mind of students were in the good category with a percentage of $75.39 \%$
\end{abstract}

Keywords :

Habits of Mind, Profile

\section{PENDAHULUAN}

Menghadapi bonus demografi Indonesia yang diprediksi akan datang pada tahun 2020-2030, seharusnya dapat menjadi harapan baru bagi kemajuan bangsa Indonesia, khususnya dalam pertumbuhan ekonomi. Data statistik (Databoks, 2016) menunjukkan bahwa jumlah usia produktif di Indonesia (15-39 tahun) sebesar 84,75 juta dari 258 juta penduduk Indonesia. Harapan tersebut disebabkan oleh salah satu faktor, bahwa generasi ini (usia 15-39 tahun) atau disebut dengan generasi millenial lahir dan berkembang di era digital, high technology, dan dalam kesehariannya tidak bisa lepas dari berbagai perangkat digital atau platform online (Ideannisa, 2017).
Oleh sebab itu, perlu mempersiapkan generasi millenial agar tidak hanya memiliki kecerdasan kognitif namun juga harus memiliki karakter yang baik. Karakter baik tersebut dapat dibentuk oleh kebiasaankebiasaan yang dilakukannya dalam kehidupan sehari-hari. Karakter tersebut juga dapat dibentuk dalam proses pendidikan, salah satunya adalah Habits of Mind (kebiasaan berpikir). Hal ini sejalan dengan Kurikulum 2013 edisi Revisi yang menuntut adanya integrasi antara PPK (Pendidikan Penguatan Karakter), 4C (Creative, Critical Thingking, Communication, dan Collaboration), HOTS (Higher Order Thingking Skill), dan Literasi.

Pembelajaran matematika berperan untuk membiasakan siswa berpikir atau 


\section{$\pi$ (Phi)}

Habits of Mind (Dwika, 2017). Pendapat serupa juga disampaikan oleh Russefendi (Dwika, 2017) bahwa "Matematika itu penting sebagai alat bantu, sebagai ilmu (bagi ilmuwan), sebagai pembimbing pola pikir maupun sebagai pembentuk sikap."

Habits of Mind memiliki peranan penting dalam proses pembelajaran dan perkembangan individu dalam memecahkan masalah. Kebiasaan ini yang menjadi akar kekuatan siswa dalam melatih kemampuan mereka dalam menemukan solusi dari permasalahan yang dihadapi. Hal ini senada dengan pendapat Campbell (Muflihatussyarifah, 2016) bahwa habits of mind sebagai karakteristik perilaku berpikir cerdas yang paling tinggi dalam memecahkan masalah dan merupakan indikator kesuksesan dalam akademik, pekerjaan, dan hubungan sosial.

Habits of Mind dikembangkan oleh Arthur L. Costa dan Benna Kallick pada tahun 1985, kemudian dilanjutkan oleh Robert J.Marzano pada tahun 1992. Habits of Mind atau kebiasaan berpikir adalah karakteristik dari apa yang dilakukan oleh orang cerdas ketika mereka dihadapkan pada permasalahan yang tidak dapat diselesaikan dengan mudah (Costa dan Kallick, 2008), yang memungkinkan untuk melakukan suatu tindakan produktif (Susanti, 2013). Habits of Mind juga diartikan sebuah perilaku yang mensinergikan kecerdasan intelektual dan emosional ketika melakukan sesuatu (Susanti, 2013). Kebiasaan berpikir ini akan membantu kesuksesan seseorang dalam memecahkan masalahnya.

Habits of Mind adalah salah satu output dari proses pembelajaran. Hal ini dikarenakan, ketika siswa telah melewati proses pembelajaran, maka kebiasaannya akan tampak mengalami perubahan. Kebiasaan tersebut jika dilatih secara terus menerus akan menjadi karakter dalam diri individu tersebut untuk mengembangkan potensi dirinya. Ini sejalan dengan makna pendidikan dalam UU No.20 tahun 2003 tentang Sistem Pendidikan Nasional bahwa pendidikan adalah usaha sadar dan terencana untuk mewujudkan suasana belajar dan proses pembelajaran agar peserta didik secara aktif mengembangkan potensi dirinya untuk memiliki kekuatan spiritual keagamaan, pengendalian diri, kepribadian, kecerdasan, akhlak mulia, serta keterampilan yang diperlukan oleh dirinya, masyarakat, bangsa dan negara.

Habit of Mind adalah tingkatan tertinggi dalam pendidikan (Costa, 2008), yaitu: (1) materi, yang berkaitan dengan penguasaan konsep dari suatu pelajaran; (2) keterampilan berpikir, yang dilatih dalam proses pembelajaran dengan meminta siswa untuk menganalisis atau membuat suatu kesimpulan dari suatu materi pelajaran; (3) menguasai tugas kognitif, yang akan melatih siswa untuk melakukan pemikiran yang mendalam; dan (4) Habit of Mind, yang membantu siswa dalam mencapai kesuksesannya.

Menurut pendapat Marzano (Nuryani, 2008) habits of mind menjadi dikategorikan menjadi 3 kelompok yaitu: self regulation, critical thinking dan creative thinking. Self regulation meliputi: (a) menyadari pemikirannya sendiri, (b) membuat rencana secara efektif, (c) menyadari dan menggunakan sumber-sumber informasi yang diperlukan, (d) sensitif terhadap umpan balik, dan (e) mengevaluasi keefektifan tindakan. Critical thinking meliputi: (a) akurat dan mencari akurasi, (b) jelas dan mencari kejelasan, (c) bersifat terbuka, (d) menahan diri dari sifat impulsif, (e) mampu menempatkan diri ketika ada jaminan, (f) bersifat sensitif dan tahu kemampuan temannya. Creative thinking meliputi: (a) dapat melibatkan diri dalam tugas meski jawaban dan solusinya tidak segera nampak, (b) melakukan usaha semaksimal kemampuan dan pengetahuannya, (c) membuat, menggunakan, memperbaiki standar evaluasi yang dibuatnya sendiri, (c) menghasilkan cara baru melihat situasi yang berbeda dari cara biasa yang berlaku pada umumnya. 


\section{$\pi$ (Phi)}

Habits of Mind pada mahasiswa memberikan manfaat yang banyak. Penerapan Habits of Mind akan membantu mahasiswa untuk memanfaatkan waktunya secara produktif dan mengasah kecerdasan mahasiswa, sehingga mahasiswa dapat belajar secara terarah, teratur, dan tepat guna, dan mendapatkan pengetahuan secara bermakna (Riksa, 2016) Oleh sebab itu, kebiasan berpikir dan pola pikir (terutama dalam belajar) perlu dikembangkan dalam kehidupan sehari-hari.

Mengingat urgensi Habits of Mind siswa dalam menentukan kesuksesan mahasiswa, maka perlu untuk mengetahui profil Habits of Mind mahasiswa program studi pendidikan matematika. Sejauh ini belum diketahui karena belum adanya penelitian tentang hal tersebut. Sehingga dapat menjadi data awal untuk mengembangkan Habits of Mind mahasiswa.

Berdasarkan uraian di atas, peneliti tertarik untuk melakukan penelitian awal tentang profil Habits of Mind mahasiswa program studi pendidikan matematika FKIP UNBARI. Oleh sebab itu, peneliti akan melakukan penelitian dengan judul "Profil Habits of Mind Mahasiswa Program Studi Pendidikan Matematika FKIP UNBARI

\section{METODE PENELITIAN}

Penelitian ini merupakan penelitian deksriptif dengan pendekatan kuantitatif, yang merupakan metode penelitian tanpa memberikan perlakuan, manipulasi, atau perubahan pada variabel bebas, tetapi menggambarkan suatu kondisi secara apa adanya.

Populasi dalam penelitian ini adalah seluruh mahasiswa program studi pendidikan matematika FKIP UNBARI. Teknik sampling dilakukan secara random sampling. Penentuan jumlah sampel berdasarkan tabel yang dikembangkan oleh Isaac dan Michael untuk tingkat kesalahan $5 \%$.

Pengumpulan data dilakukan dengan menggunakan kuesioner Habits of Mind yang diadaptasi dari indikator Habits of Mind's Costa and Kallick yang disebarkan secara online melalui bantuan Google Form.

Teknik analisis data yang digunakan dalam penelitian ini adalah analisis deskriptif kuantitatif. Untuk mengetahui persentase skor jawaban hasil angket Habits of Mind ditentukan dengan rumus:

Keterangan:

$$
\%=\frac{\boldsymbol{n}}{\boldsymbol{N}} \times 100 \%
$$

$n=$ skor empirik yang diperoleh

$N=$ Jumlah skor ideal

$\%=$ persentase yang diperoleh

Adapun kriteria analisis deskriptif persentase (Riduan, 2009) adalah sebagai berikut.

Tabel 4. Kriteria Analisis Deskriptif Persentase

\begin{tabular}{ccc}
\hline No & $\begin{array}{c}\text { Rentang } \\
\text { Presentase }\end{array}$ & Kriteria \\
\hline 1 & $81,25 \%<\% \leq$ & Sangat Baik \\
& $100 \%$ & \\
2 & $62,25 \%<\% \leq$ & Baik \\
& $81,25 \%$ & \\
3 & $43,75 \%<\% \leq$ & Cukup Baik \\
4 & $62,25 \%$ & Tidak Baik \\
\hline
\end{tabular}

\section{HASIL DAN PEMBAHASAN}

Penelitian ini bertujuan untuk mengetahui profil Habits of Mind mahasiswa program studi pendidikan matematika. Data yang diperlukan dalam penelitian ini dikumpulkan dengan menggunakan angket yang terdiri dari 23 item pernyataan yang dijawab oleh responden dengan menggunakan skala Likert: sangat seringsering-kadang-kadang-jarang-tidak pernah.

Sampel dalam penelitian ini adalah mahasiswa prodi pendidikan matematika FKIP UNBARI sebanyak 33 orang, yang terdiri dari 90,9\% perempuan dan 9,1\% lakilaki. Mahasiswa yang mengisi angket ini terdiri dari 18,2\% mahasiswa semester III, $30,3 \%$ mahasiswa semester $\mathrm{V}$, dan $30,3 \%$ mahasiswa semester VII, serta $21,2 \%$ mahasiswa yang sedang dalam proses menyelesaikan tugas akhir. 


\section{$\pi$ (Phi)}

Dari hasil analisis angket diperoleh bahwa habits of mind mahasiswa berada dalam persentase $75,39 \%$ dengan interpreatsi baik. Hal ini menunjukkan bahwa habits of mind mahasiswa program studi pendidikan matematika FKIP UNBARI dengan skor baik. Artinya mahasiswa prodi pendidikan matematika memiliki kebiasaan berpikir yang baik. Namun kemampuan afektif ini masih perlu untuk ditingkatkan. Karena kebiasaan berpikir adalah suatu perilaku yang terbentuk berdasarkan proses pembelajaran dalam waktu yang relatif lama.

Berikut ini disajikan hasil analisis angket berdasarkan indikator habits of mind:

\section{Berteguh Hati}

Tabel 1a. Persentasi Hasil Angket HoM Berdasarkan

\begin{tabular}{clcc}
\multicolumn{3}{c}{ Indikator } & \\
\hline No & $\begin{array}{c}\text { Item } \\
\text { Pernyataan }\end{array}$ & Presentase & Interpretasi \\
\hline 1 & $\begin{array}{l}\text { Saya } \\
\text { mengerjakan } \\
\text { tugas sampai } \\
\text { tuntas }\end{array}$ & $92 \%$ & Sangat Baik \\
\hline 2 & $\begin{array}{l}\text { Saya tidak } \\
\text { pernah mencoba } \\
\text { cara/strategi } \\
\text { baru jika } \\
\text { cara/strategi } \\
\text { yang digunakan } \\
\text { gagal }\end{array}$ & $58 \%$ & Cukup \\
\hline & & \\
\hline Rata-rata & $75 \%$ & Baik \\
\hline
\end{tabular}

Berdasarkan tabel diatas diperoleh bahwa habits of mind mahasiswa pada indikator berteguh hati sebesar $75 \%$ yang berada dalam kategori baik. Mahasiswa mampu mengerjakan tugas yang diberikan sampai tuntas namun cukup baik dalam mencari/mencoba strategi baru jika strategi yang digunakan gagal. Hal ini berarti sebesar $42 \%$ mahasiswa berhenti mengerjakan tugas ketika strategi yang digunakan gagal.

\section{Mengendalikan Impulsivitas}

Tabel 1b. Persentasi Hasil Angket HoM Berdasarkan Indikator

\begin{tabular}{cccc}
\hline No & $\begin{array}{c}\text { Item } \\
\text { Pernyataan }\end{array}$ & Presentase & Interpretasi \\
\hline 3 & Saya berpikir & $88 \%$ & Sangat Baik \\
\hline
\end{tabular}

Jurnal Pendidikan Matematika Volume 3 Nomor 2 Tahun 2019

\begin{tabular}{llll}
\hline No & $\begin{array}{c}\text { Item } \\
\text { Pernyataan }\end{array}$ & Presentase & Interpretasi \\
\hline & sebelum \\
& $\begin{array}{l}\text { mengerjakan } \\
\text { sesuatu }\end{array}$ & \\
\hline
\end{tabular}

Berdasarkan tabel diatas diperoleh bahwa habits of mind mahasiswa pada indikator mengendalikan impulsivitas sebesar $88 \%$ yang berada dalam kategori sangat baik. Mahasiswa mampu mengendalikan tindakannya, dengan berpikir sebelum bertindak.

\section{Mendengarkan dengan Pengertian dan Empati}

Tabel 1c. Persentasi Hasil Angket HoM Berdasarkan Indikator

\begin{tabular}{clcc}
\hline No & \multicolumn{1}{c}{$\begin{array}{c}\text { Item } \\
\text { Pernyataan }\end{array}$} & Presentase & Interpretasi \\
\hline 4 & $\begin{array}{l}\text { Saya melakukan } \\
\text { aktivitas lain } \\
\text { (bermain hape, }\end{array}$ & & \\
& menggambar, & & \\
mengobrol & $68 \%$ & Baik \\
dengan teman) & & \\
ketika dosen & & \\
menjelaskan & & \\
materi di kelas & & \\
\hline
\end{tabular}

Berdasarkan tabel diatas diperoleh bahwa habits of mind mahasiswa pada indikator mendengarkan dengan pengertian dan empati sebesar $68 \%$ yang berada dalam kategori baik. Hal ini menunjukkan bahwa sebagian besar mahasiswa mendengarkan dengan penuh pengertian dan empati, dan sebesar $32 \%$ mahasiswa yang tidak mendengarkan dengan penuh pengertian dan empati.

\section{Berpikir Fleksibel}

Tabel 1d. Persentasi Hasil Angket HoM Berdasarkan Indikator

\begin{tabular}{clcc}
\hline No & $\begin{array}{c}\text { Item } \\
\text { Pernyataan }\end{array}$ & Presentase & Interpretasi \\
\hline 5 & $\begin{array}{l}\text { Saya pasif } \\
\text { ketika sesi } \\
\text { brainstorming } \\
\text { (curah } \\
\text { pendapat) di } \\
\text { kelas }\end{array}$ & $67 \%$ & Baik \\
\hline
\end{tabular}




\section{$\pi$ (Phi)}

\begin{tabular}{clcc}
\hline No & $\begin{array}{c}\text { Item } \\
\text { Pernyataan }\end{array}$ & Presentase & Interpretasi \\
\hline \multirow{2}{*}{$\begin{array}{l}\text { Saya tertarik } \\
\text { dengan } \\
\text { pelajaran yang } \\
\text { berhubungan } \\
\text { dengan analisis }\end{array}$} & $68 \%$ & Baik \\
\hline & Rata-rata & $67,5 \%$ & Baik \\
\hline
\end{tabular}

Berdasarkan tabel diatas diperoleh bahwa habits of mind mahasiswa pada indikator berpikir fleksibel sebesar 67,5\% yang berada dalam kategori baik. Hal ini menunjukkan bahwa mahasiswa cukup mampu berpikir fleksibel, namun masih harus lebih ditingkatkan melalui proses pembelajaran.

\section{Berpikir tentang Berpikir / Metakognisi}

Tabel 1e. Persentasi Hasil Angket HoM Berdasarkan Indikator

\begin{tabular}{clcc}
\hline No & $\begin{array}{c}\text { Item } \\
\text { Pernyataan }\end{array}$ & Presentase & Interpretasi \\
\hline 7 & $\begin{array}{l}\text { Saya } \\
\text { mengetahui apa } \\
\text { yang saya } \\
\text { pikirkan }\end{array}$ & $85 \%$ & Sangat Baik \\
\hline 8 & $\begin{array}{l}\text { Saya tidak } \\
\text { mampu } \\
\text { mengungkapkan } \\
\text { apa yang saya } \\
\text { pikirkan dengan } \\
\text { baik }\end{array}$ & $52 \%$ & Cukup \\
\hline & & \\
\hline
\end{tabular}

Berdasarkan tabel diatas diperoleh bahwa habits of mind mahasiswa pada indikator metakognisi sebesar $68,5 \%$ yang berada dalam kategori baik. Hal ini menunjukkan bahwa sebesar $68,5 \%$ mahasiswa memahami apa yang ia pikirkan. Hal ini ditunjukkan dari hasil angket, bahwa sebesar $85 \%$ mahasiswa mengetahui apa yang mereka pikirkan. Namun mereka masih kesulitan dalam mengungkapkan apa yang mereka pikirkan. Sehingga diperlukan pembelajaran yang dapat memfasilitasi siswa agar mampu mengungkapkan apa yang mereka pikirkan.

\section{Memeriksa Akurasi}

Jurnal Pendidikan Matematika

Volume 3 Nomor 2 Tahun 2019

Tabel 1f. Persentasi Hasil Angket HoM Berdasarkan Indikator

\begin{tabular}{|c|c|c|c|}
\hline No & $\begin{array}{c}\text { Item } \\
\text { Pernyataan }\end{array}$ & Presentase & Interpretasi \\
\hline 9 & $\begin{array}{l}\text { Saya } \\
\text { mengecek } \\
\text { proyek, tugas, } \\
\text { dan ujian } \\
\text { secara } \\
\text { berulang-ulang }\end{array}$ & $85 \%$ & Sangat Baik \\
\hline 10 & $\begin{array}{l}\text { Saya meminta } \\
\text { bantuan teman } \\
\text { untuk } \\
\text { mengoreksi } \\
\text { hasil pekerjaan } \\
\text { saya }\end{array}$ & $73 \%$ & Baik \\
\hline 11 & $\begin{array}{l}\text { Saya biasa saja } \\
\text { ketika tidak } \\
\text { mengerjakan } \\
\text { tugas dengan } \\
\text { benar dan } \\
\text { tuntas }\end{array}$ & $76 \%$ & Baik \\
\hline & Rata-rata & $78 \%$ & Baik \\
\hline
\end{tabular}

Berdasarkan tabel diatas diperoleh bahwa habits of mind mahasiswa pada indikator memeriksa akurasi sebesar 78\% yang berada dalam kategori baik. Hal ini menunjukkan bahwa mahasiswa mampu dengan baik dalam meemeriksa keakuratan.

\section{Mempertanyakan dan Menemukan Permasalahan}

Tabel 1g. Persentasi Hasil Angket HoM Berdasarkan Indikator

\begin{tabular}{clcc}
\hline No & $\begin{array}{c}\text { Item } \\
\text { Pernyataan }\end{array}$ & Presentase & Interpretasi \\
\hline 12 & $\begin{array}{l}\text { Saya malu } \\
\text { mengajukan } \\
\text { pertanyaan } \\
\text { tentang hal-hal } \\
\text { yang tidak } \\
\text { diketahui }\end{array}$ & $66 \%$ & Baik \\
\hline
\end{tabular}

Berdasarkan tabel diatas diperoleh bahwa habits of mind mahasiswa pada indikator mempertanyakan dan menemukan permasalahan sebesar $66 \%$ yang berada dalam kategori baik. Hal ini menunjukkan mahasiswa mengajukan pertanyaan untuk menemukan permasalahan ataupun menyelesaikan permasalahan yang mereka hadapi. 
8. Menggunakan Pengetahuan Masa Lalu di Situasi Baru

Tabel 1h. Persentasi Hasil Angket HoM Berdasarkan Indikator

\begin{tabular}{clcc}
\hline No & $\begin{array}{c}\text { Item } \\
\text { Pernyataan }\end{array}$ & Presentase & Interpretasi \\
\hline 13 & $\begin{array}{l}\text { Saya belajar } \\
\text { dari } \\
\text { pengalaman }\end{array}$ & $88 \%$ & Sangat Baik \\
\hline
\end{tabular}

Berdasarkan tabel diatas diperoleh bahwa habits of mind mahasiswa pada indikator menggunakan pengetahuan masa lalu disituasi baru sebesar $88 \%$ yang berada dalam kategori sangat baik. Hal ini terlihat dari hasil angket bahwa sebagian besar mahasiswa mampu belajar dari pengalaman.

\section{Berpikir dan Berkomunikasi Secara Jelas dan Cermat}

Tabel 1i. Persentasi Hasil Angket HoM Berdasarkan

\begin{tabular}{c|l|c|c}
\multicolumn{4}{c}{ Indikator } \\
\hline No & Item Pernyataan & Presentase & Interpretasi \\
\hline 14 & $\begin{array}{l}\text { Saya tidak mampu } \\
\text { mengkomunikasikan } \\
\text { (secara } \\
\text { verbal/tulisan) } \\
\text { pemikiran saya } \\
\text { dengan baik }\end{array}$ & $64 \%$ & Baik \\
\hline
\end{tabular}

Berdasarkan tabel diatas diperoleh bahwa habits of mind mahasiswa pada indikator berpikir secara jelas dan cermat sebesar 64\% yang berada dalam kategori baik. Hal ini menunjukkan bahwa mahasiswa mampu mengkomunikasikan apa yang dipikirkannya dengan baik.

\section{Mencari dengan Semua Indra}

Tabel 1j. Persentasi Hasil Angket HoM Berdasarkan

\begin{tabular}{clcc}
\multicolumn{3}{c}{ Indikator } & \\
\hline No & $\begin{array}{c}\text { Item } \\
\text { Pernyataan }\end{array}$ & Presentase & Interpretasi \\
\hline 15 & $\begin{array}{l}\text { Saya } \\
\text { mengumpulkan } \\
\text { semua informasi } \\
\text { dengan semua } \\
\text { panca indera }\end{array}$ & $73 \%$ & Baik \\
\hline
\end{tabular}

Berdasarkan tabel diatas diperoleh bahwa habits of mind mahasiswa pada indikator mencari dengan semua indera sebesar $783 \%$ yang berada dalam kategori baik. Hal ini menunjukkan bahwa mahasiswa mampu memanfaatkan inderanya untuk mengumpulkan informasi yang ia butuhkan.

\section{Mencipta, Berimajinasi, Inovasi}

Tabel 1k. Persentasi Hasil Angket HoM Berdasarkan Indikator

\begin{tabular}{clcc}
\hline No & $\begin{array}{l}\text { Item } \\
\text { Pernyataan }\end{array}$ & Presentase & Interpretasi \\
\hline 16 & $\begin{array}{l}\text { Saya tidak } \\
\text { mampu } \\
\text { menciptakan } \\
\text { produk, solusi } \\
\text { dan cara baru } \\
\text { yang cerdas } \\
\text { dan kreatif }\end{array}$ & $65 \%$ & Baik \\
\hline 17 & $\begin{array}{l}\text { Saya tidak } \\
\text { mampu } \\
\text { memberikan } \\
\text { solusi untuk } \\
\text { masalah secara } \\
\text { berbeda }\end{array}$ & $67 \%$ & Baik \\
\hline Rata-rata & $66 \%$ & Baik \\
\hline
\end{tabular}

Berdasarkan tabel diatas diperoleh bahwa habits of mind mahasiswa pada indikator mencipta, berimajinasi, dan berinovasi sebesar $66 \%$ yang berada dalam kategori baik. Ini berarti mahasiswa FKIP mampu untuk menghasilkan suatu produk baru, namun masih diperlukan bimbingan yang lebih intens dalam proses pembelajaran.

\section{Merepon dengan Kekaguman}

Tabel 11. Persentasi Hasil Angket HoM Berdasarkan Indikator

\begin{tabular}{cccc}
\hline No & $\begin{array}{c}\text { Item } \\
\text { Pernyataan }\end{array}$ & Presentase & Interpretasi \\
\hline 18 & $\begin{array}{l}\text { Saya memiliki } \\
\text { rasa ingin tahu } \\
\text { yang tinggi }\end{array}$ & $81 \%$ & Sangat Baik \\
\hline
\end{tabular}

Berdasarkan tabel diatas diperoleh bahwa habits of mind mahasiswa pada indikator memeriksa akurasi sebesar $81 \%$ yang berada dalam kategori sangat baik. Hal ini menunjukkan bahwa mahasiswa mampu dengan baik dalam meemeriksa keakuratan. 


\section{Bertanggung Jawab Terhadap Resiko yang ada \\ Tabel 1m. Persentasi Hasil Angket HoM Berdasarkan Indikator

\begin{tabular}{clcc}
\hline No & Item Pernyataan & Presentase & Interpretasi \\
\hline 19 & $\begin{array}{l}\text { Saya mampu } \\
\text { bertanggungjawab }\end{array}$ & & \\
& $\begin{array}{l}\text { atas semua } \\
\text { tindakan yang }\end{array}$ & $85 \%$ & Sangat Baik \\
& dilakukan & & \\
\hline
\end{tabular}

Berdasarkan tabel diatas diperoleh bahwa habits of mind mahasiswa pada indikator bertanggungjawab terhadap resiko yang ada sebesar $85 \%$ yang berada dalam kategori sangat baik. Hal ini menunjukkan bahwa mahasiswa mampu mempertanggungjawabkan apa yang telah dilakukannya.

\section{Humoris}

Tabel 1n. Persentasi Hasil Angket HoM Berdasarkan Indikator

\begin{tabular}{|c|c|c|c|}
\hline No & $\begin{array}{c}\text { Item } \\
\text { Pernyataan }\end{array}$ & Presentase & Interpretasi \\
\hline 20 & $\begin{array}{l}\text { Saya memiliki } \\
\text { selera humor }\end{array}$ & $74 \%$ & Baik \\
\hline
\end{tabular}

Berdasarkan tabel diatas diperoleh bahwa habits of mind mahasiswa pada indikator humoris sebesar $74 \%$ yang berada dalam kategori baik.

\section{Berpikir Ketergantungan}

Tabel 1o. Persentasi Hasil Angket HoM Berdasarkan Indikator

\begin{tabular}{clcc}
\hline No & $\begin{array}{c}\text { Item } \\
\text { Pernyataan }\end{array}$ & Presentase & Interpretasi \\
\hline 21 & $\begin{array}{l}\text { Saya tidak } \\
\text { peduli dengan } \\
\text { tugas } \\
\text { kelompok }\end{array}$ & $93 \%$ & Sangat Baik \\
\hline 22 & $\begin{array}{l}\text { Saya senang } \\
\text { belajar dalam } \\
\text { kelompok }\end{array}$ & $77 \%$ & Baik \\
\hline & Rata-rata & $85 \%$ & Sangat Baik \\
\hline
\end{tabular}

Berdasarkan tabel diatas diperoleh bahwa habits of mind mahasiswa pada indikator berpikir ketergantungan sebesar
$85 \%$ yang berada dalam kategori sangat baik.

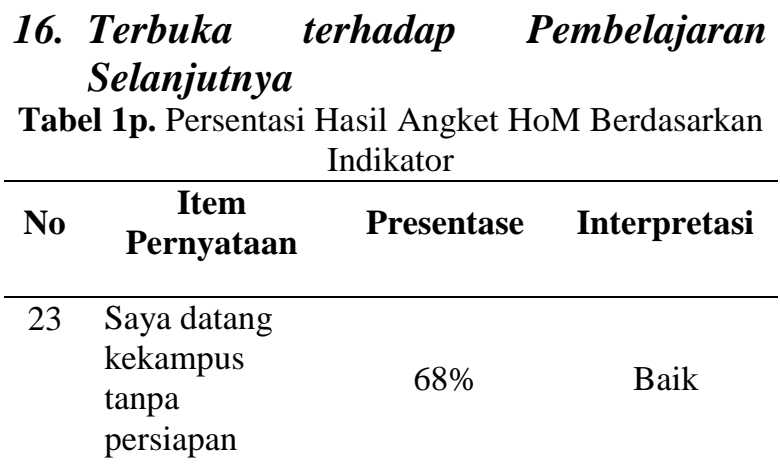

Berdasarkan tabel diatas diperoleh bahwa habits of mind mahasiswa pada indikator terbuka tehadap pembelajaran selanjutnya sebesar $68 \%$ yang berada dalam kategori baik.

\section{SIMPULAN DAN SARAN}

Berdasarkan hasil penelitian, diperoleh hasil bahwa habits of mind mahasiswa program studi pendidikan matematika FKIP UNBARI adalah baik, dengan persentase sebesar 75,39\%. Namun masih diperlukan pengembangan lebih lanjut dalam proses pembelajaran, dikarenakan kemampuan afektif mahasiswa dikembangkan dalam waktu yang relatif lama.

Dengan demikian, disarankan untuk dapat mengembangkan habits of mind lebih lanjut dalam proses pembelajran dengan melibatkan berbagai strategi/model pembelajaran yang sesuai,

\section{DAFTAR PUSTAKA}

Costa, A., Kallick, B. 2008. Leading And Learning With Habits Of Mind 16 Essential Characteristic For Success.United States Of America: Association For Supervision And Curriculum Development (ASCD)

Databoks. 2016, 24 Sep. Usia Produktif Dominasi Penduduk Indonesia 2016. Diperoleh 30 Desember 2018 dari http://Databoks.Katadata.Co.Id 
Dwika, EM. 2017. Asosiasi Kemampuan Pemecahan Masalah dan Mathematical Habits Of Mind Siswa SMP. Jurnal Penelitian Pendidikan INSANI, Volume 20, Nomor 1, Juni 2017, Hlm. 38-44

Ideannisa. 2017, 4 May. Mengenal Indonesia Lewat Data: Generasi Millenial dan Terbukanya Peluang Ekonomi Baru Indonesia. Diperoleh 30 Desember 2018 dari http://Ideannisa.Com/2017/05/04/Pelu ang-Ekonomi-Bonus-DemografiMillenial/

Muflihatussyarifah. (2016). Visual Thingking Dan Habits Of Striving For Accuracy And Precesion Siswa Melalui Model CORE Disertai Aktivitas Quick On The Draw. Tesis Sps UPI Bandung: Tidak Diterbitkan

Nuryani. 2008. Pendidikan Dan Penelitian Sains Dalam Mengembangkan Keterampilan Berpikir Tingkat Tinggi Untuk Pengembangan Karakter.Seminar Nasional VII Pendidikan Biologi. Tersedia di http://jurnal.fkip.uns.ac.id/index.php/p rosbio/article/view/748/416

Riduan. 2009. Metode dan Teknik Penyusunan Proposal Penelitian. Bandung: Alfabeta

Riksa, I. 2016. Profil Tingkatan Habits Of Mind dan Kecemasan Kognitif dalam Mata Pelajaran Biologi Pada Siswa SMA di Kota Bandung. Biodidaktika, Volume 11 No 2,

Susanti, Ely. 2013. Soal High Order Thinking Skill Untuk Melatih Kebiasaan Berpikir Matematis. Tersedia di http://eprints.unsri.ac.id/5691/1/SEMN AS_UNSRI_16_MEI.pdf. 